\title{
Demographic and medical characteristics of hospitalised oldest old
}

\begin{abstract}
Objective: To study demographic and medical characteristics of hospitalised oldest old.

Method: A retrospective audit of patients aged $\geq 80$ years admitted to a Geriatric Unit in a tertiary hospital in Perth, Western Australia.

Results: There were 257 patients accounting for 287 admissions ( $84.3 \%$ nonagenarians, $14.3 \%$ octogenarians and $1.4 \%$ centenarians). Mean age was 91.6 years, $73.2 \%$ were female and $62.0 \%$ were admitted from the community. The 3 commonest admission diagnoses were: falls/trauma, cardiovascular disease and neuropsychiatric disease. Percent with a documented history of falls was $82.2 \%$, osteoporosis $44.9 \%$, urinary incontinence $38.3 \%$, cognitive impairment $42.5 \%$, delirium $44.9 \%$ and depression $32.1 \%$. In-hospital, 1 -year and 2-year mortality rates were $9.1 \%, 41.5 \%$ and $51.6 \%$, respectively.
\end{abstract}

Conclusion: Hospitalised oldest old studied at our institute were predominantly community-dwelling females presenting with falls/trauma, cardiovascular disease and neuropsychiatric disease. They were a frail population with multiple co-morbidities, a high prevalence of the "Geriatric Giants" and very high mortality rates.

Keywords: aged 80 and over, centenarians, nonagenarians, octogenarians, oldest old
Volume 3 Issue 3 - 2018

\author{
Charles A Inderjeeth, Kellie R Hanna \\ Department of Rehabilitation and Aged Care, University of \\ Western Australia, Australia
}

\begin{abstract}
Correspondence: Charles A Inderjeeth, Clinical Professor Charles Inderjeeth, Department of Rehabilitation and Aged Care, University of Western Australia, G174B, C Block, QE2 Medical Centre Hospital Avenue, Nedlands,WA, 6909,Australia, Tel (08) 64573333, Fax (08) 645728II,

Email Charles.inderjeeth@health.wa.gov.au
\end{abstract}

Received: October 29, 2017| Published: June II, 2018

\section{Keypoints}

i. There is a need for more clinical information about the $\geq 85$ year's age group of Australia's population, the most rapidly expanding segment of the population.

ii. Hospitalised oldest old are predominantly communitydwelling females.

iii. The 3 commonest admission diagnoses and co-morbid medical problems of hospitalised oldest old at our institute were: falls/ trauma, cardiovascular disease and neuropsychiatric disease.

iv. Hospitalised oldest old are a frail population with multiple comorbidities, a high prevalence of the "Geriatric Giants" and very high mortality rates.

\section{Introduction}

Australia's population is ageing, as a result of sustained low fertility and increasing life expectancy. ${ }^{1,2}$ Important factors contributing to increasing life expectancy are improved living conditions and improved treatment and rehabilitation of chronic illnesses. ${ }^{3}$ The consequence is an increasing proportion of Australia's population aged $\geq 85$ years, the population's most rapidly expanding segment. This is demonstrated in data from the Australian Bureau of Statistics. ${ }^{1,2}$ Between June 1985 and June 2005, the proportion of Australia's population aged $\geq 85$ years increased by $102 \%(0.74 \% \rightarrow 1.5 \%) .{ }^{1}$ In $2005-2006$, the average annual rate of growth for the $\geq 85$ years age group was $8.02 \%$, compared with $1.31 \%$ for all ages. ${ }^{2}$

Over the next several decades, population ageing is expected to have significant implications for health care in Australia. Increasing numbers of nonagenarians, the predominant age group analysed in this study, will present to emergency departments and many will require subsequent admission to hospital..$^{4-6}$ Emergency department and hospital visits by nonagenarians are associated with prolonged admissions, post-discharge institutionalisation, and high risk of in-hospital and post-discharge death. ${ }^{4}$ Decline in functional status is commonly observed. ${ }^{5,7}$ Community support services are often required. There is a need for more clinical information about this group, which is actively using social and health care. ${ }^{9}$

Nonagenarians are generally quite frail and have numerous chronic diseases with associated functional and cognitive impairment. ${ }^{4,9}$ The "Geriatric Giants" ("Immobility", "Instability", "Incontinence", "Intellectual impairment" and "Iatrogenesis") are commonplace. These are all complex problems resulting from a combination of diminished organ reserve and the effects of acute and chronic diseases on the ageing body and mind. ${ }^{10}$

There is very limited published literature describing the characteristics of hospitalised nonagenarians in Australia. To our knowledge, only one Australian study has comprehensively looked at the demographic and medical characteristics of hospitalised nonagenarians. ${ }^{11}$

Other published studies relating to nonagenarians have tended to focus on specific patient groups or medical problems. ${ }^{12-19}$ Some focused on emergency department visits; 4,5 patients on rehabilitation units, ${ }^{21}$ or institutionalised patients. ${ }^{22}$ Most were community or population based. ${ }^{9,15-18,23-25}$

The primary objective of this study is to document the demographic and medical characteristics of the oldest old (i.e. octogenarians, 
nonagenarians and centenarians) admitted to a Geriatric Unit of a tertiary hospital.

\section{Method}

\section{Study design and patients}

This project was approved as a Quality Assurance (QA) case note audit by the ethics committee of Sir Charles Gairdner Hospital.

The study involved a retrospective audit of patients admitted to a Geriatric Evaluation and Management Unit (the Unit) in a tertiary hospital in Perth, Western Australia, over a 6 month period.

All patients aged $\geq 80$ years, who were inpatients on the Unit under the care of a Geriatrician, were included in the study.

During the study period, all acute medical patients were admitted to an Acute Assessment Unit (AAU). Patients requiring care beyond the AAU were referred to Geriatric Medicine for ongoing care if they were $\geq 90$ years or $<90$ years and deemed to require "geriatric-type" multidisciplinary care. The majority of these patients were managed on the Unit.

Patients were occasionally admitted to the Unit directly from the Outpatient Clinic, the community or another hospital. Patients requiring a period of rehabilitation prior to discharge were transferred from the Unit to an off-site affiliated Rehabilitation Unit once medically stable. The Unit, therefore, admitted a mixture of acute and subacute patients and patients requiring rehabilitation who were not deemed appropriate to be transferred off-site (e.g. medically unstable patients, delirious patients requiring a surveillance guard, dialysis patients and amputees).

This study excluded: patients on the Unit aged $<80$ years; patients on the Unit under the care of other specialty physicians; and, patients aged $\geq 80$ years admitted under the care of a Geriatrician but not managed on the Unit.

\section{Data collection}

Data was collected by retrospective review of patient case notes by a single observer. Information was collected from a combination of medical, nursing and allied health records.

Data collected included patient demographic characteristics, referral source, admission diagnosis, co-morbid medical problems, data relating to "Geriatric Giants" ("Immobility \& Instability" mobility, use of walking aids, Functional Independence Measure (FIM) score, falls \& fracture history; "Incontinence" - urinary \& faecal; "Intellect"- dementia, Mini-Mental State Examination (MMSE) score, delirium, Confusion Assessment Method (CAM) score, depression, 5- item Geriatric Depression Scale (GDS) score; and, "Iatrogenesis" - number \& type of medications at admission \& discharge), length of hospital admission and mortality.

\section{Statistical analysis}

Data was entered into SPSS version 14.0 for statistical analysis.

\section{Results}

During the 6 month study period, (1 March 2005 - 31 August 2005), there was a total of 287 admissions of patients fulfilling the inclusion criteria. These 287 admissions were accounted for by 257 different patients, of whom 230 had 1 admission, 26 had 2 admissions, and 1 had 5 admissions.

\section{Patient demographic characteristics}

Of the study group, $73.2 \%$ were female. Patients' age ranged between 79-104 years, with mean age 91.6 years (Two patients were aged 79 years at the time of admission but had turned 80 by the 1 March 2005 when the analysis commenced). Nonagenarians accounted for $84.3 \%$, octogenarians $14.3 \%$ and centenarians $1.4 \%$.

Prior to admission, $62.0 \%$ of patients were community-dwelling and $38.0 \%$ were from residential care facilities $(28.6 \%$ hostel; $8.7 \%$ nursing home) or psycho-geriatric lodges $(0.7 \%)$. At least $21.3 \%$ had a change in social situation on discharge from the Unit. Post-discharge, $30.7 \%$ of patients returned directly to community-dwelling and $38.4 \%$ directly to a residential care facility $(18.5 \%$ hostel; $19.9 \%$ nursing home). There was a more than 2 -fold increase in those transferred directly to a nursing home. Twenty-two percent were transferred to the affiliated Rehabilitation Unit or psycho-geriatric units prior to their final discharge destination.

\section{Referral source}

The AAU was the major referral source for patients aged $\geq 90$ years. In those aged $<90$ years, one third were referred from each of the AAU, Medical Units and other sources.

\section{Admission diagnosis}

In the study patients, the commonest admission diagnosis was falls/trauma, followed by cardiovascular disease, neuropsychiatric disease and respiratory disease (Table 1). For those patients with an admission diagnosis of falls/trauma, $38.4 \%$ had an associated fracture documented.

\section{Co-morbid medical problems}

In addition to admission diagnosis, patient case notes were reviewed for a history of documented co-morbid medical problems (Table 2).

Table I Admission diagnosis

\begin{tabular}{lll}
\hline Admission diagnosis & $\begin{array}{l}\text { No. patients } \\
(\mathrm{n}=287)\end{array}$ & $\begin{array}{l}\text { Percent } \\
(\%)\end{array}$ \\
\hline Falls/trauma & 86 & 30.0 \\
Cardiovascular disease & 59 & 20.6 \\
Neuropsychiatric disease & 56 & 19.5 \\
Respiratory disease & 36 & 12.5 \\
Gastrointestinal disease & 22 & 7.7 \\
Genitourinary disease & 13 & 4.5 \\
Oncologic/haematological disease & 7 & 2.4 \\
Rheumatologic/bone disease & 4 & 1.4 \\
$\begin{array}{l}\text { Endocrine/metabolic/nutritional } \\
\text { disease }\end{array}$ & 2 & 0.7 \\
Dermatological disease & 2 & 0.7 \\
\hline
\end{tabular}


Table 2 Co-morbid medical problems

\begin{tabular}{lll}
\hline Medical problem & $\begin{array}{l}\text { No. patients } \\
(\mathrm{n}=287)\end{array}$ & $\begin{array}{l}\text { Percent } \\
(\%)\end{array}$ \\
\hline Neuropsychiatric disease & 232 & 80.8 \\
Sensory impairment & 211 & 73.5 \\
Cardiovascular disease & 251 & 87.5 \\
Respiratory disease & 116 & 40.4 \\
Gastrointestinal disease & 170 & 59.2 \\
Genitourinary disease & 206 & 71.8 \\
Endocrine/metabolic/nutritional disease & 191 & 66.6 \\
Rheumatologic/bone disease & 196 & 68.3 \\
Dermatological disease & 14 & 4.9 \\
Oncologic/haematological disease & 103 & 35.9 \\
Falls/trauma & 236 & 82.2 \\
\hline
\end{tabular}

\section{Geriatric giants}

\section{Immobility \& Instability}

Pre-admission, $81.5 \%$ of patients were described as independently ambulant. This proportion decreased to $48.4 \%$ at the time of discharge. Approximately $20 \%$ of patients were transferred to Rehabilitation Units, with the aim of improving mobility and functional independence.

FIM scores are tabulated in Table 3 . Only $46.3 \%$ of patients had serial FIM scores performed. Mean gain in total FIM score in those with serial FIM scores was $5.24 \pm 15.5$. This gain was almost entirely due to gains in motor FIM score.

A history of falls was common, with $82.2 \%$ of patients having a documented history of falls. At least $38.7 \%$ had recurrent falls. A documented history of minimal trauma fracture/s was present in $42.2 \%$ of patients. The most frequently documented fracture types were hip (17.8\%), vertebral (13.6\%), pelvic $(9.1 \%)$ and wrist $(9.1 \%)$ Of note, only documented vertebral fractures were identified and asymptomatic or radiological fractures were not reviewed.

\section{Incontinence}

Documented urinary incontinence was present in $38.3 \%$ of patients pre-admission and $36.6 \%$ at discharge. Documented faecal incontinence was present in $21.3 \%$ pre-admission and $21.6 \%$ at discharge.

\section{Intellect (dementia/delirium/depression)}

In total, $42.5 \%$ of patients had documentation of "dementia" or "cognitive impairment". MMSE scores were recorded in $49.5 \%$ (Table 4).

A documented history of "delirium", or clinical picture suggestive of delirium, was present in $44.9 \%$ of patients. Documentation of CAM scores was poor $(3.8 \%)$.

"Depression" was documented in $32.1 \%$ of patients. Table 5 presents the GDS scores.

\section{Iatrogenesis}

Polypharmacy was common, with number of medications ranging from 0-18 at admission and 0-19 at discharge. Mean number of medications was 6.70 (SD 3.39) at admission and 7.74 (SD 3.21) at discharge. Table 6 shows types of medications.

\section{Length of hospital admission}

For the study patients, hospital length of stay ranged between 1-207 days, with a mean of 19.25 days and median of 12.00 days (Table 7).

\section{Mortality}

We reviewed hospital notes and databases for mortality data. Inhospital mortality was $9.1 \%$. By 6 months after admission, $30.0 \%$ of patients had died; by 12 months $41.5 \%$ had died; and, by 24 months $51.6 \%$ had died (Table 8). These rates may be an underestimate as hospital records are not as accurate as death records for mortality.

Table 3 Functional Independence Measure (FIM) Score

\begin{tabular}{llllllllll}
\hline & \multicolumn{3}{l}{ Baseline FIM score } & \multicolumn{3}{c}{ Repeat FIM score } & \multicolumn{3}{c}{ FIM gain } \\
\cline { 2 - 9 } & Motor & Cognitive & Total & Motor & Cognitive & Total & Motor & Cognitive & Total \\
\hline $\mathrm{n}$ & 187 & 187 & 205 & 119 & 119 & 133 & 119 & 119 & 133 \\
Missing & 100 & 100 & 82 & 168 & 168 & 154 & 168 & 168 & 154 \\
Range & $12-91$ & $5-42$ & $17-126$ & $13-85$ & $5-36$ & $18-117$ & $-23-49$ & $-17-18$ & $-32-57$ \\
Mean & 45.21 & 21.70 & 67.60 & 47.30 & 20.71 & 69.53 & 4.59 & 0.05 & 5.24 \\
Median & 45.00 & 22.00 & 67.00 & 46.00 & 20.00 & 71.00 & 3.00 & 0.00 & 3.00 \\
Std.dev & 19.46 & 8.49 & 25.92 & 19.81 & 8.08 & 25.60 & 12.32 & 4.72 & 15.50 \\
\hline
\end{tabular}

Table 4 Mini-Mental State Examination (MMSE) scores according to patient group

\begin{tabular}{llll}
\hline & \multicolumn{3}{c}{ MMSE score } \\
\cline { 2 - 4 } & All patients & Age $<\mathbf{9 0}$ years & Age $\geq \mathbf{9 0}$ years \\
\hline $\mathrm{n}$ & 142 & 27 & 115 \\
Missing & 145 & 14 & 131 \\
Range & $1-30$ & $6-28$ & $1-30$ \\
Mean & 19.39 & 19.04 & 19.47 \\
Median & 20.00 & 21.00 & 20.00 \\
Std.dev & 6.55 & 6.51 & 6.58 \\
\hline
\end{tabular}


Table 5 Geriatric Depression Scale (GDS) scores according to patient group

\begin{tabular}{llll}
\hline \multirow{2}{*}{ GDS scores } & & \\
\cline { 2 - 4 } & All patients & Age $<\mathbf{9 0}$ years & Age $\geq \mathbf{9 0}$ years \\
\hline $\mathrm{n}$ & 103 & 20 & 83 \\
Missing & 184 & 21 & 163 \\
Range & $0-5$ & $0-5$ & $0-5$ \\
Mean & 1.91 & 2.15 & 1.86 \\
Median & 2.00 & 2.00 & 2.00 \\
Std.dev & 1.56 & 1.39 & 1.60 \\
\hline
\end{tabular}

Table 6 Types of medications (admission \& discharge)

\begin{tabular}{|c|c|c|c|c|}
\hline \multirow[t]{2}{*}{ Medications } & \multicolumn{2}{|c|}{ Admission medications } & \multicolumn{2}{|c|}{ Discharge medications } \\
\hline & No.patients & Percent (\%) & No.patients & Percent (\%) \\
\hline Cholinesterase inhibitors/memantine & II & 3.8 & 9 & 3.1 \\
\hline Anti-Parkinsons & I & 0.3 & 3 & 1.0 \\
\hline Antidepressants & 72 & 25.1 & 79 & 27.5 \\
\hline Anxiolytics/sedatives/ hypnotics & 82 & 28.6 & 69 & 24.0 \\
\hline Antipsychotics & 32 & II.I & 29 & 10.1 \\
\hline Anticoagulants & 13 & 4.5 & 16 & 5.6 \\
\hline Antihypertensives/antianginal/ antiarrhythmic & 193 & 67.2 & 180 & 62.7 \\
\hline Diuretics & 108 & 37.6 & 100 & 34.8 \\
\hline Lipid lowering agents & 43 & 15.0 & 38 & 13.2 \\
\hline Respiratory medications & 35 & 12.2 & 29 & 10.1 \\
\hline Antacids/antiemetics & 121 & 42.2 & 126 & 43.9 \\
\hline Hormonal therapy & 14 & 4.9 & 13 & 4.5 \\
\hline Bisphosphonates & 34 & 11.8 & 45 & 15.7 \\
\hline Calcium & 81 & 28.2 & 103 & 35.9 \\
\hline Vitamin $d$ & 91 & 31.7 & 114 & 39.7 \\
\hline Corticosteroids & 7 & 2.4 & 7 & 2.4 \\
\hline Immunosuppressants/ chemotherapy & 4 & 1.4 & 4 & 1.4 \\
\hline Antibiotics & 40 & 13.9 & 39 & 13.6 \\
\hline Opioid analgesics & 33 & 11.5 & 44 & 15.3 \\
\hline Non-opioid analgesics & 117 & 40.8 & 170 & 59.2 \\
\hline Antiinflammatories & 24 & 8.4 & 21 & 7.3 \\
\hline Aperients & 89 & 31.0 & 139 & 48.4 \\
\hline Other & 97 & 33.8 & 95 & 33.1 \\
\hline
\end{tabular}

Table 7 Length of hospital admission

\begin{tabular}{llll}
\hline \multicolumn{2}{l}{ Length of hospital admission (days) } \\
\cline { 2 - 4 } & All patients & Age $<90$ years & Age $\geq \mathbf{9 0}$ years \\
\hline $\mathrm{n}$ & 287 & $4 \mathrm{I}$ & 246 \\
Range & $\mathrm{I}-207$ & $4-207$ & $1-92$ \\
Mean & 19.25 & 40.29 & 15.74 \\
Median & 12.00 & 28.00 & 11.00 \\
Mode & 7.00 & 9.00 & 7.00 \\
Std.dev & 21.28 & 39.64 & 13.63 \\
\hline
\end{tabular}

Table 8 Mortality

\begin{tabular}{|c|c|c|c|c|c|c|c|c|c|c|}
\hline & \multicolumn{4}{|c|}{ Deceased status } & \multirow{2}{*}{\multicolumn{2}{|c|}{$\begin{array}{l}\text { Deceased } \\
\text { between } \\
6-12 \text { months } \\
\text { after admission }\end{array}$}} & \multirow{2}{*}{\multicolumn{2}{|c|}{$\begin{array}{l}\text { Deceased between } \\
\text { I 2-24 months after } \\
\text { admission }\end{array}$}} & \multirow{2}{*}{\multicolumn{2}{|c|}{$\begin{array}{l}\text { Cumulative number } \\
\text { deceased within } 24 \\
\text { months after admission }\end{array}$}} \\
\hline & \multicolumn{2}{|c|}{$\begin{array}{l}\text { Deceased } \\
\text { during } \\
\text { admission }\end{array}$} & \multicolumn{2}{|c|}{$\begin{array}{l}\text { Deceased within } \\
6 \text { months after } \\
\text { admission }\end{array}$} & & & & & & \\
\hline & No. & $\%$ & No. & $\%$ & No. & $\%$ & No. & $\%$ & No. & $\%$ \\
\hline $\begin{array}{l}\text { All } \\
\text { patients } \\
(n=287)\end{array}$ & 26 & 9.1 & 60 & 20.9 & 33 & 11.5 & 29 & 10.1 & 148 & 51.6 \\
\hline
\end{tabular}


Deceased status

\begin{tabular}{|c|c|c|c|c|}
\hline $\begin{array}{l}\text { Deceased } \\
\text { during } \\
\text { admission }\end{array}$ & $\begin{array}{l}\text { Deceased within } \\
6 \text { months after } \\
\text { admission }\end{array}$ & $\begin{array}{l}\text { Deceased } \\
\text { between } \\
6-12 \text { months } \\
\text { after admission }\end{array}$ & $\begin{array}{l}\text { Deceased between } \\
\text { I 2-24 months after } \\
\text { admission }\end{array}$ & $\begin{array}{l}\text { Cumulative number } \\
\text { deceased within } 24 \\
\text { months after admission }\end{array}$ \\
\hline
\end{tabular}

\begin{tabular}{lccccccccc}
\hline & No. & $\%$ & No. & $\%$ & No. & $\%$ & No. & $\%$ & No. \\
\hline $\begin{array}{l}\text { Age } \\
<90 \text { years } \\
(n=4 I)\end{array}$ & 4 & 9.8 & 6 & 14.6 & 2 & 4.9 & 6 & 14.6 & 18 \\
$\begin{array}{l}\text { Age } \\
\geq 90 \text { years } \\
(n=246)\end{array}$ & 22 & 8.9 & 54 & 22.0 & 31 & 12.6 & 23 & 9.3 & 130 \\
\hline
\end{tabular}

\section{Discussion}

Australia's population is ageing and the most rapidly expanding segment of the population is the $\geq 85$ years age group. ${ }^{1,2}$ Over the next several decades, population ageing is expected to have significant implications for health care in Australia. Gaps in our knowledge about the oldest-old exist, particularly with regards to hospitalised nonagenarians in Australia. To our knowledge, only one other study ${ }^{11}$ has focused on hospitalised nonagenarians in Australia. There is a need for more clinical information about this group, which disproportionately contributes to social and health care costs. ${ }^{9}$

\section{Patient demographics}

This study comprised of a large group of the oldest-old who were hospitalised under the care of a Geriatric Unit in a tertiary hospital. Although we expected this to be a frailer cohort living in residential care, the majority of patients in this cohort were: female $(73.2 \%)$; community-dwelling prior to admission $(62.0 \%)$; and, only admitted to the index catchment hospital once during the 6 month study period $(89.5 \%)$. We did not have access to information regarding admission to other hospitals, which may make this an under-estimate of the readmissions within 6 months. Hospitalisation precipitated a change in accommodation status to a higher level of care in at least a fifth of patients. The proportion transferred to nursing home care more than doubled. The final discharge destination of the $20 \%$ who were transferred to the Rehabilitation Unit is unknown. It is probable that a proportion of these would have required a higher level of care (including nursing home care) compared to pre-admission, further adding to the burden of care.

These patient demographic characteristics are similar to those from the study at Flinders Medical Centre, Adelaide, South Australia. They found that the majority of patients were: women (73\%), communitydwelling (52\%), only admitted to hospital once during the 12 month study period (69\%); and, median age was 92 years. ${ }^{11}$ Studies in other countries have also found that the majority of nonagenarians are

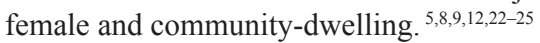

\section{Admission diagnosis \& co-morbid medical problems}

The 3 commonest admission diagnoses (as well as the most frequently documented co-morbid medical problems) were: falls/ trauma, cardiovascular disease and neuropsychiatric disease, as expected in this population. Orthopaedic and cardiovascular problems were also found to be the major admission diagnoses in the other Australian study. ${ }^{11}$

\section{Geriatric giants}

\section{Immobility"\& "Instability}

"Immobility" and, particularly, "Instability" were clearly "Geriatric Giants" in this study group. Although the majority of patients were reported as independently ambulant pre-admission, this number decreased significantly at the time of discharge. Both the medical condition prompting admission and the hospital admission itself are likely to have contributed to this reduction in mobility.

Inpatient care was associated with an improvement in serial FIM scores in some patients and deterioration in others. Overall, however, there was an improvement in total FIM score of 5.24 points, predominantly due to gains in the motor component. Other studies have also shown that gains in FIM score are predominantly due to gains in the motor component. In a study by Kevorkian et al., ${ }^{22}$ mean gain in total FIM score was 14.42 points (almost entirely due to gains in motor FIM score), significantly higher than in our study. However, the latter study related to nonagenarians on a Rehabilitation Unit, where higher gains in motor FIM score would be expected.

A very high proportion (82.2\%) of patients had a documented history of falls, with recurrent falls in at least $38.7 \%$. Falls/trauma was the commonest admission diagnosis, being the primary diagnosis in $30.0 \%$ of admissions. Falls/trauma are prominent in many studies focusing on nonagenarians. ${ }^{4,8,11,13,14}$

As expected, a high proportion of patients had documented osteoporosis (44.9\%) and minimal trauma fractures (42.2\%), with a significant female predominance for osteoporosis $(57.1 \%$ versus $11.7 \%$ ) and fracture (54.3\% versus $9.1 \%)$. These figures are likely to be an under-estimate, as asymptomatic fractures (particularly vertebral) are less likely to be diagnosed and documented.

\section{Incontinence}

High frequencies of incontinence (urinary \& faecal) were documented. Proportions did not change significantly by discharge, suggesting chronicity and lack of reversibility.

\section{Intellectual impairment (dementia/delirium/depression)}

Documentation of dementia or cognitive impairment was present in $42.5 \%$ of patients and was higher in females $(46.2 \%$ versus $32.5 \%)$. 
Higher prevalence of dementia/cognitive impairment in females has been demonstrated in many studies. ${ }^{15-18,24}$ Prevalence of dementia increases with increasing age. This is well demonstrated in a large (1 424 people), community-based, population study in Sweden, which showed an increase in the prevalence of dementia from $13 \%$ in 77 84 year olds, to $37 \%$ in $90-94$ year olds, to $48 \%$ in $\geq 95$ year olds. ${ }^{17}$ Börjesson-Hanson et al., ${ }^{15}$ studied the prevalence of dementia in 95 year olds. They determined the prevalence to be $51.5 \%$, and higher in women (55\% versus $37 \%)$. ${ }^{15}$ In a Rochester study of 111 patients aged 90-100 years, $49.5 \%$ were found to have Mild Cognitive Impairment or dementia. ${ }^{16}$ Our results are consistent with the aforementioned studies. In a community-based, cross-sectional study of the oldest old ( $\geq 90$ years) living in Stockholm, Sweden, prevalence of dementia and cognitive impairment (MMSE <24) were $42.2 \%$ and $63.8 \%$ for females, and $24.7 \%$ and $47.1 \%$ for males, respectively. ${ }^{24}$ Our study is likely to have under-estimated the prevalence of cognitive impairment, as the presence of mild cognitive impairment is not always documented and MMSE was only performed on half of the patients.

A documented history of delirium, or clinical picture suggestive of delirium, was present in $44.9 \%$. Recording of CAM scores was poor, making interpretation unreliable.

Depression was documented in $32.1 \%$ of patients. This is lower than a study previously conducted at this institution, which suggested possible depressive symptoms in $42.7 \%$ of hospitalised elderly and $53.3 \%$ of community-dwelling elderly [20]. In the current study, prevalence of depression was based on documentation of depression rather than on GDS scores (which were only recorded in $35.9 \%$ ). It is possible that the diagnosis may have been missed as patients were not screened. Our results, however, are higher than studies using strict criteria for depression. A number of patients are labelled with "depression" despite not strictly fulfilling diagnostic criteria. A population-based study of 329 nonagenarians in Stockholm, Sweden, found the prevalence of Major Depressive Episode (using DSM-IV criteria) to be $7.9 \%$, and the prevalence of mild/moderate/severe Depressive Episode (using ICD-10 criteria) to be $9.1 \% .{ }^{19}$

\section{Iatrogenesis}

Polypharmacy was common and hospitalisation did not result in a reduction in polypharmacy. However, there was a change in types of medications prescribed that may be deemed appropriate. Hospital admission was associated with an increase in the number of patients prescribed vitamin D, calcium and bisphosphonates. Despite this, the proportion on treatment at the time of discharge remained suboptimal. There was a decrease in the prescription of cardiovascular medications and anxiolytics/sedatives/hypnotics. Falls and fracture prevention/ protection may have been the major reason for some of these changes.

\section{Length of hospital admission}

As expected, there was a wide variation in the length of hospital admission (1-207 days). The longer length of stay of the cohort of patients aged $<90$ years may be reflective of the admission criteria for the Unit. The Unit accepted all types of medical patients aged $\geq 90$ years, including patients who required acute or subacute care, as well as patients requiring rehabilitation who were unsuitable for transfer to the off-site Rehabilitation Unit. For patients aged $<90$ years, the Unit generally only accepted the latter type of patient. Results were skewed by 5 patients aged $<90$ years with prolonged length of stay who were unsuitable for transfer off-site ( 2 amputees and 3 delirious patients).

\section{Mortality}

Estimated mortality was quite high in this cohort, with an inhospital, 6 month and 12 month mortality of $9 \%, 30 \%$ and $42 \%$ respectively. Only half of the patients were alive by 2 years. Inhospital mortality reported was similar to the South Australian study. ${ }^{11}$ A higher total in-hospital mortality of $23.1 \%$ (5.5\% emergency department mortality and $17.6 \%$ in-hospital mortality) and a slightly higher 1-year mortality (49.2\%) were reported in the Japanese study. ${ }^{4}$

\section{Study limitations and strengths}

This study has some limitations. There may be a selection bias as we did not assess patients aged $\geq 90$ years who were not admitted to the Unit. As a retrospective audit, it is reliant on the accuracy of documentation in case notes. Some information, particularly relating to co-morbid medical problems and "Geriatric Giants", may be incomplete and may under-estimate their true extent. It is also possible that patients may not fulfil all diagnostic criteria for a particular diagnosis, leading to an over-estimate of their true prevalence. Interpretation by the reviewer was required when there was conflicting data in the notes or when symptoms suggestive of a diagnosis, rather than an actual diagnosis, were listed (e.g. delirium and cognitive impairment). MMSE, CAM and GDS scores were poorly recorded.

The major strengths of this study are two-fold. Firstly, selection bias was minimised by the study including the great majority of nonagenarians requiring medical admission, (beyond the 72 hour limit of the AAU), to the tertiary teaching hospital involved. Secondly, information was collected from a combination of medical, nursing and allied health records by a single observer. This improved the completeness and accuracy of data and avoided inter-observer variability in data interpretation.

\section{Conclusion}

This study comprehensively documents the demographic and medical characteristics of a large group of the oldest-old (predominantly nonagenarians), hospitalised under the care of a Geriatric Unit. On the whole, this patient population is quite frail, with multiple co-morbid medical problems, a high prevalence of the Geriatric Giants, and alarmingly high mortality rates, including inhospital, 1-year and 2-year mortality rates. Hospitalisation appears to be a significant marker of frailty, morbidity and mortality risk.

\section{Acknowledgements}

None.

\section{Conflict of interest}

The author declares no conflict of interest.

\section{References}

1. Australian Bureau of Statistics. Population by age and sex, Australian states and territories, Jun 2005. Canberra: Australian Bureau of Statistics; Catalogue No. 3201. 2005.

2. Australian Bureau of Statistics. Population by age and sex, Australian states and territories, Jun 2006. Canberra: Australian Bureau of Statistics; Catalogue No. 3201.0. 2006

3. Kalache A. Ageing worldwide. In: Ebrahim S, Kalache A, editors. Epidemiology in old age. London: British Medical Journal, 1996;22-31. 
4. Mitsunaga I, Masafumi K, Yoshimi K, et al. Emergency department use by nonagenarian patients. Geriatrics \& Gerontology International. 2006;6:25-31

5. Formiga F, Vidaller A, Salazar A, et al. Functional decline in nonagenarians after a visit to an ED [Letters to the Editor]. American Journal of Emergency Medicine. 2003;21(6):509.

6. Patterson C, Crescenzi C, Steel K. Hospital use by the extremely elderly (nonagenarians): a two-year study. Journal of the American Geriatrics Society. 1984;32:350-352.

7. Sager MA, Franke T, Inouye SK et al. Functional outcomes of acute medical illness and hospitalization in older persons. Archives of Internal Medicine. 1996; 156: 645-652.

8. Formiga F, Mascaró J, Pujol R et al. Natural history of functional decline 1 year after hospital discharge in nonagenarian patients [Letters to the Editor]. Journal of the American Geriatrics Society. 2003;51:1040 1047.

9. Goebeler S, Jylha M, Hervonen A. Medical history, cognitive status and mobility at the age of 90: a population-based study in Tampere, Finland. Aging Clinical and Experimental Research. 2003;15:154-161.

10. Sherman FT. The geriatric giants: Don't miss their footprints!. Geriatrics. 2003;58:8.

11. Harris JH, Finucane PM, Healy DC, et al. Use of inpatient hospita services by people aged 90-99 years. Medical Journal of Australia. 1997; 167:417-420.

12. Pelavski AD, Colomina MJ, Miguel $\mathrm{M}$, et al. Demographics of nonagenarians and centenarians with a hip fracture [Letters to the Editor]. Anesthesia \& Analgesia. 2006;103:1597-1599.

13. Dangleben D, Salim A, Grossman D, et al. Nonagenarians and trauma: an increasingly common combination [Letters to the Editor]. Journal of the American Geriatrics Society. 2005;53:729-731.

14. Sieling BA, Hofmann MT, Beem K, et al. Trauma in nonagenarians and centenarians: review of 137 consecutive patients. Journal of the American Geriatrics Society. 2003;70(9):793-6.

15. Börjesson HA, Edin E, Gislason T, et al. The prevalence of dementia in 95 year olds. Neurology. 2004;63:2436-2438.
16. Boeve B, McCormick J, Smith G et al. Mild cognitive impairment in the oldest old. Neurology 2003; 60: 477-480.

17. Strauss E, Viitanen M, Ronchi D, et al. Aging and the occurrence of dementia: findings from a population-based cohort with a large sample of nonagenarians. Archives of Neurology. 1999;56:587-592.

18. Crystal HA, Dickson D, Davies P, et al. The relative frequency of "dementia of unknown etiology" increases with age and is nearly $50 \%$ in nonagenarians. Archives of Neurology. 2000;57:713-719.

19. Forsell Y, Strauss E, Winblad B, et al. Prevalence and correlates of depression in a population of nonagenarians. British Journal of Psychiatry. 1995;167(1):61-64.

20. Nguyen HV, Inderjeeth CA, Tang E, et al. Screening for depression in hospitalised and community-dwelling elderly: the use of the 4-item, 5-item and 15-item geriatric depression scales. Australasian Journal on Ageing. 2006;25:204-208.

21. Alanen H-M, Finne SH, Noro A, et al. Use of antipsychotics among nonagenarian residents in long-term institutional care in Finland. Age \& Ageing. 2006;35:508-513

22. Kevorkian CG, Ergeletzis D, Rintala D. Nonagenarians on a rehabilitation unit: characteristics, progress, and outcomes. American Journal of Physical Medicine \& Rehabilitation. 2004;83(4):266-272.

23. Formiga F, Pujol R, Perez CJM, et al. Low comorbidity and male sex in nonagenarian community-dwelling people are associated with better functional and cognitive abilities: the NonaSantfeliu study. Journal of the American Geriatrics Society 2005;53(10):1836-1837.

24. von Strauss E, Fratiglioni L, Viitanen $M$ et al. Morbidity and comorbidity in relation to functional status: a community-based study of the oldest old (90+ years). Journal of the American Geriatrics Society. 2000;48(11):1462-1469.

25. Nybo H, Gaist D, Jeune B et al. The Danish 1905 cohort: a geneticepidemiological nationwide survey. Aging Health. 2001;13(1):32-46. 